\title{
Simple but effective LIS research: Why we need it, and how we can do it
}

Paul Sturges

\section{Introduction (In a Paris café)}

One afternoon in July 1978 I was sitting at a pavement table outside a café on the Boulevard St Michel in Paris. This may sound like a 'What I did on my holidays' story, but in fact I was working on a small qualitative research project. Earlier that afternoon I had done an interview with a scholar just around the corner in the Sorbonne. I had not taped the interview, and had only scribbled a few words and names into my notebook whilst it was in progress. What I was doing in the café was writing up an account of the interview (on paper in those pre-laptop days). Whether this was the first interview I had done in this way I can't remember, but I do know that I was very happy with the results that my simple technique produced. It certainly wasn't what the contemporary manuals on research technique advised, but I found that it worked. In what follows I shall offer some thoughts about LIS research methods from the perspective of someone who has much more faith in the qualitative than the quantitative, and who believes that the imaginative devising and matching of methods to circumstances in the field is a skill that should be encouraged. Since you will find that I concentrate very much on the downside of LIS research in this little paper, I should say at the outset that I do encounter a great deal of very good output from all sorts of sources, but that's not really what I will write about here.

\section{Informal interviews}

I had come to develop and use an informal interview method for entirely pragmatic reasons. Tape recorders in those days were mainly large clumsy machines that dominated any encounter in which they were used. I had found that interview subjects were much more relaxed without a whirring machine on the table. Since I didn't have shorthand, I had the choice of trying to write down almost everything my interviewees said in longhand, or only making rudimentary notes that would provide prompts for my memory. The alternative of trying to write down everything was clearly impossible; it would have made for the most stilted exchanges that you could imagine. I therefore chose the latter alternative. For this purpose the interview script with which I worked consisted of a minimal set of questions, plus possible supplementaries and prompts. Because it was short

\footnotetext{
Author

Paul Sturges is a history graduate who learned social science methodology by doing. He has researched an eclectic mix of LIS topics in many countries. He is Chair of IFLA FAIFE.
}

Email: r.p.sturges@1boro.ac.uk 
and simple I seldom needed to look at it during interviews, but it did enable me to ensure that in the course of the naturally flowing conversation that this method produced, I didn't forget anything that I'd intended to ask the subject. The reliance on taking the briefest of notes made it possible to maintain eye contact with the interview subject and to allow the interview to take a natural course.

This might sound like the recipe for an unholy mess, but this has never proved to be the case. An interviewer who really listens will not only encourage the interviewee, but will remember the content of the interview much more clearly than if he or she was relying on a machine to do the work, or was desperately trying to produce a written record of some sort (short or long hand). I found that writing up the notes almost immediately after the interview took place, or at least within 24 hours, resulted in a record that was short, structured and informative. Topics that occurred more than once in the interview could be dealt with in a single coherent passage of the record. Possible ambiguity in what the interviewee's actual words seemed to convey could be made clear in the light of remembered body language, facial expression and tone of voice. What the interviewee thought was important could emerge better than if the interview were to be written up on the basis of the interviewer's pre-devised structure and the interviewee's literal sequence of responses. The final advantage was that the long, often difficult, process of transcription of tapes or a shorthand record was dispensed with. A series of interviews done on this basis had as its end result a set of compact and highly usable pieces of research data.

In later years I have used this method to good effect in very different sets of circumstances. For instance, in 1995 I had the opportunity to work in cooperation with the National Library of Malawi on a small project concerned with information dissemination to the rural population. (Sturges and Chimseu, 1996) Funding for this came mainly in the form of a few hundred pounds from the local branch of the British Council, although the National Library, by making a talented young librarian available to assist me, contributed generously in kind. We went out into villages and farming areas interviewing agricultural extension workers and conducting focus groups with members of farming families. Sitting under a tree by the side of a red dust road in the middle of nowhere listening to the ideas and experiences of an (almost literally) barefoot information worker was a rich and fascinating experience. Now in $2008 \mathrm{I}$ am conducting similar interviews with stand up comedians in an exploration of comedy as freedom of expression and performers' perceived limitations to their freedom. In these and other circumstances it works well. It fits the needs of particular projects and enables me to carry out cheap and effective research.

Are there any disadvantages to this method? Of course there are. For a start it makes it impossible to include verbatim quotations from the interview subjects in the finished report or article. However, if one asks oneself whether quotations are so much better than reported speech, the answer might well be that while quotations often add something, they are often introduced to bolster the researcher's insecurity and add very little that would not be provided by reported speech. More significant than the inability to quote is the fact that the method introduces the subjectivity of the researcher to a very much greater extent than methods which produce a full and literal record that can potentially be audited for 
veracity. This is a strong and genuine objection to which the researcher can only respond by fully accepting that the reader's trust in the research material must be based on its inherent credibility. With this method, the reader is asked to decide whether the material is credible or not and whether the researcher deserves to be trusted. This is actually not such a big barrier as it might sound; any research should be read with a sceptical and enquiring eye. This is equally true whether the research asks for the reader's trust, or demands it on the basis of mountains of statistics and factual appendices.

\section{Finding appropriate research methods}

A question that this account of my interviewing technique raises is whether we should rely on the advice we get from teachers and manuals, or experiment with techniques that may not appear from these sources of guidance. As you might imagine from the previous section, I strongly believe that young researchers should be encouraged to think creatively about their methods. This may well lead them to experiment with ideas on techniques that are generated by the needs of a project rather than taken from the established repertoire. This may involve them in reinventing some comparatively obscure form of wheel. For a research beginner this doesn't really matter. It is more important that they go through a creative process than find an account of appropriate technique in the literature. When they come to investigate further they may well find previous use of the technique and even find that it is dignified with a name. Not so long ago a young Polish researcher asked me if a technique that she was intending to use seemed sound, and if it had a name. I replied that it certainly sounded worthwhile, but that I didn't know of a name for it. Enquiries among colleagues pretty soon established that it was referred to as 'transaction logging' and had been fairly frequently used. But the important thing to me was that she had come to the idea independently and had worked out how to do it herself.

Something similar proved to be true of the interviewing method that I first used in 1978. I might well have felt at the time that I had invented it. In the sense that I had worked out how I would do my interviews, and had built my own rationale to support this, I could at least claim to have come to it independently. However, around that time I discovered a description and rationale for the method written by one of the great nineteenth century social researchers, Beatrice Webb (1926, Appendix: The method of the interview, 361-3). Of course, Webb was working in the days before electronic technology was available, but her justification for the method is not that it is cheap and easy, but that it has genuine virtues. Similarly, whilst I was happy that she endorsed, even recommended, the technique, it didn't change my feeling that I liked it because it worked and was appropriate to need.

To some people, the suggestion that young researchers should not always rely exclusively on what they have been taught might probably sound like heresy and a formula for the production of research that lacks rigour. If the teaching of research methods in LIS was perfect, that might be true. However, more than 30 years of exposure to LIS dissertations and theses, reports, conference papers and articles has convinced me that this is very far from the case. Examples I have encountered on a very regular basis, mainly but not entirely from developing countries, have convinced me that there is a great deal of narrow, unimaginative and sometimes 
thoroughly bad teaching of research methods. This is made worse in circumstances where libraries do not hold a good range of manuals on research technique. A real horror story illustrates the point.

Sometime in the mid 1990s I was external examiner for a number of Masters dissertations at an LIS department in the most prestigious university of a developing country. Each dissertation began with some general remarks on research techniques for LIS. Almost without exception they reported that there were three techniques: the literature search, the questionnaire and the interview. The list of modules that the students had taken included one on research methods taught by an Indian professor, who prided himself on having been a pupil of Ranganathan. Presumably Ranganathan hadn't taught him the idiocy that he was peddling to whole cohorts of rather talented students. Because I knew what the students had been exposed to, I was particularly impressed by the work of one of them. He had been tasked with a dissertation project that would include the devising of an information system for a major government agency in the country. He hadn't actually got as far as saying much on the structure of a proposed system. What he had done was to go through the organisation meticulously identifying information and communication resources, and their lack. When I asked him if he knew what he had done, he was rather shame-faced at not having really completed his assigned task. He was also quite unaware that he had reinvented the information and communications audit, and had carried out a masterly exercise in the use of the technique under circumstances of considerable difficulty. Unfortunately, not all young researchers in developing countries, and those from more privileged environments, have this student's combination of imagination and common sense.

\section{LIS research technique reconsidered}

The discipline of LIS is a young one and it depends for its research inspiration to a great extent on the broader social sciences. There is a certain amount in the LIS field that can be done by measurement - citation studies obviously spring to mind - but I would suggest that almost all that is of real interest defies stricter quantitative work, or gains little from it. Such a big assertion clearly requires thorough justification, but on this occasion I will simply leave my readers to decide whether or not they find it credible. What is presumably rather less likely to provoke outrage is the suggestion that quantitative research works best on big problems addressed by surveys of big populations, with high response rates. The small but interesting, topics and tentative, exploratory projects, which are most typical of the current state of LIS research, all respond best to qualitative work. Rather than defend this position here, I will go on to make some remarks about the deficiencies of the research process in LIS that arise to some extent out of what I have already said about quantitative methods.

First of all, I have the impression that LIS research methods have too often been taught by people who are not experienced and enthusiastic researchers themselves. This is the most credible explanation I can find for the bias towards quantitative methods in what is taught. To support my conviction that this bias exists, I can only cite the reflexive spasm that seems to occur straight after a young researcher has identified a topic. The words 'Now I will draw up the questionnaire' pop out 
almost before account has been taken of any other considerations. Just what the topic requires in terms of data, and how that data might best be assembled, seem all too often to be missed out in the rush to survey some people, somewhere, about something or other that might or might not be helpful. Maybe teachers of research methods concentrate their teaching hours on questionnaire surveys because they are genuinely a difficult form to use and do require that neophyte researchers receive a good deal of instruction. Designing a good questionnaire, identifying and contacting an appropriate survey population, and organising and interpreting survey data are none of them easy. However, it doesn't look like that is the reason for concentrating on surveys. Surveys actually seem to have been identified as an easy method, but one which will be accepted as meeting the standards of what constitutes 'proper' research.

The possibility that the survey is perceived as the defining method of LIS research would seem to be supported by fairly frequently occurring examples from amongst papers submitted to LIS journals. These take the form of articles that identify a topic, claim that a survey has been carried out and then present not anything even resembling a detailed summary of results, but rather a few pages of aggregated data, percentages, charts and tests of significance. What this is supposed to prove, other than that the writer can do it, and that his or her research supervisors and examiners have agreed that he or she can do it, is not at all obvious. Only the results and their interpretation in textual form (supported by the numbers as appropriate) have any substantial significance, but this seems to have escaped the notice of some LIS researchers. One would hope that the refereeing process would remove this type of submission from the chain, but some of it still creeps through into print.

At this point we should ask questions of referees and editors. In the past I have done this. After reading a particularly unconvincing journal article purporting to be based on a survey of unspecified numbers of Nigerian women I wrote to the editor of the journal concerned. I asked how he justified publishing an article that offered no convincing evidence, in the form of the questionnaire itself, an account of the target and responding populations and some convincing detail on results, that its survey had actually taken place. My letter received no reply. One sympathises to an extent. Even the best LIS journals experience times when suitable articles are too few in number and poorer journals must be desperate for copy most of the time. This is, however, no excuse for publishing dangerous trash. The expected standards of research in a discipline are defined in various ways. Conference presentations, and even semi-published reports might be seen as works in progress, needing to respond to less demanding standards, but the journal article should truly define what the discipline expects. At present it seems that it expects questionnaire surveys and isn't too concerned how suitable and informative these might be.

\section{Conclusion}

To return to the beginning of this paper: there is a great deal that can be done, and done well, in LIS research using simple, inexpensive methods. Qualitative research can tell us most of what we need to know on some topics and this information can be obtained using quite informal techniques, such as the 
interviewing described above. Qualitative investigations can also ground the expansion of projects that might eventually be seen to require the confirmation that can be provided by large volumes of more precise data. A rush to quantification helps very little. It can dehumanise the topic and, where research ethics are not observed, it can help to smuggle in the specious survey. On the other hand, the dangers of the qualitative are obvious. It is subjective to such an extent that it admits the possibility of being mainly opinion (cranky or biased opinion maybe) and only to a lesser degree fact. Given the truth of that, bad qualitative research is surprisingly uncommon. Maybe the sheer nakedness of the form deters the dishonest, who prefer to dress up their questionable research with the apparatus of numbers. Whatever the reasons for poor quantitative research and insufficiently ambitious qualitative research may be, in fact I feel there is a message for teachers and writers on research methods, research supervisors and examiners, referees and editors, and the information professionals to whom the literature is ultimately addressed. They should encourage resourceful thinking on research methods by young researchers. There is a great deal that we need to know about information in just about every imaginable sphere and a need for effective, practical research methods to expose it to view.

\section{References}

Sturges, P. and Chimseu, G. (1996) The Chain of Information Provision in the Villages of Malawi. International Information and Library Review, 28 (2), 135-156.

Webb, B. (1926) My apprenticeship. London: Longmans, Green and Co. 